\title{
THE ARCTIC AMPLIFICATION DEBATE
}

\author{
MARK C. SERREZE ${ }^{1}$ and JENNIFER A. FRANCIS ${ }^{2}$ \\ ${ }^{1}$ Cooperative Institute for Research in Environmental Sciences, National Snow and Ice Data Center, \\ Campus Box 449, University of Colorado, Boulder, CO 80309-0449 \\ E-mail: serreze@kryos.colorado.edu \\ ${ }^{2}$ Institute of Marine and Coastal Sciences, Rutgers University, 71 Dudley Rd., \\ New Brunswick, NJ 08901
}

\begin{abstract}
Rises in surface air temperature (SAT) in response to increasing concentrations of greenhouse gases (GHGs) are expected to be amplified in northern high latitudes, with warming most pronounced over the Arctic Ocean owing to the loss of sea ice. Observations document recent warming, but an enhanced Arctic Ocean signal is not readily evident. This disparity, combined with varying model projections of SAT change, and large variability in observed SAT over the 20th century, may lead one to question the concept of Arctic amplification. Disparity is greatly reduced, however, if one compares observed trajectories to near-future simulations (2010-2029), rather than to the doubled$\mathrm{CO}_{2}$ or late 21 st century conditions that are typically cited. These near-future simulations document a preconditioning phase of Arctic amplification, characterized by the initial retreat and thinning of sea ice, with imprints of low-frequency variability. Observations show these same basic features, but with SATs over the Arctic Ocean still largely constrained by the insulating effects of the ice cover and thermal inertia of the upper ocean. Given the general consistency with model projections, we are likely near the threshold when absorption of solar radiation during summer limits ice growth the following autumn and winter, initiating a feedback leading to a substantial increase in Arctic Ocean SATs.
\end{abstract}

\section{Introduction}

Since the mid-1800s, global average surface air temperature (SAT) has risen approximately $0.7^{\circ} \mathrm{C}$ (Jones and Moberg, 2003). It is widely believed that at least part of this warming arises from increased concentrations of infrared absorbing gases in the atmosphere, the so-called greenhouse effect. These gases absorb longwave radiation that would otherwise be lost to space, and re-radiate some of it back to the surface. Owing to feedbacks and interactions involving primarily sea ice and snow cover, greenhouse-induced warming is expected to be enhanced and accelerated in the Arctic region in comparison with that for the entire globe or Northern Hemisphere. We term this effect Arctic amplification.

Pronounced and pervasive changes have been observed in the Arctic during recent decades (e.g., Serreze et al., 2000; Overland et al., 2003). Available observations document upward trends in SAT over much of the northern high latitudes (Rigor et al., 2000; Comiso, 2003; Overland et al., 2004; ACIA, 2004; Johannessen et al., 2004) accompanied by reductions in sea ice. Since 1979, annual mean sea ice extent as recorded by satellites has declined by about $3 \%$ per decade. Ice extent in 
September (the month of the seasonal minimum) has decreased by at least twice this rate (Parkinson et al., 1999; Comiso, 2000, 2001; Cavalieri et al., 2003; Stroeve et al., 2005) and the past four Septembers (2002 through 2005) have seen extreme minima (Serreze et al., 2003; Stroeve et al., 2005; http://www.nsidc.org/data/seaice_index/). There are also indications of decreased sea ice thickness and volume (Rothrock et al., 2003; Rothrock and Zhang, 2004; Lindsay and Zhang, 2005), warming of soils and permafrost (Osterkamp and Romanovsky, 1999), increased precipitation (Groves and Francis, 2002), and rising discharge from Arctic-draining rivers in Siberia (Peterson et al., 2002). Northern Hemisphere snow cover has exhibited modest negative anomalies since the late 1980s, largely owing to spring and summer deficits, but with large interannual and spatial variability (e.g., Robinson and Frei, 2000; Armstrong and Brodzick, 2001). Arctic vegetation appears to be shifting from tundra to shrubs (Wang and Overland, 2004; Chapin et al., 2005). Other studies point to enhanced northward penetration of warm Atlantic-derived waters into the Arctic basin (e.g., Dickson et al., 2000; Karcher et al., 2003). Paleoclimate evidence suggests that the late 20th century Arctic was the warmest of the past 400 years (Overpeck et al., 1997).

Are we seeing the first signs of model-projected Arctic amplification? The answer is a matter of debate and scientific importance. The debate revolves primarily around the following issues:

Differing Model Projections: Essentially all global climate models predict Arctic amplification, and most agree that SAT changes will be especially large over the Arctic Ocean during autumn and early winter owing to sea ice retreat and thinning. There are large differences, however, among different models in their depiction of the time evolution, magnitude, and spatial patterns of SAT change. Another facet of the issue is that emerging greenhouse signals projected for the Arctic differ markedly from those for $\mathrm{CO}_{2}$ doubling or for the latter part of the 21 st century, where attention is commonly focused.

Low Frequency Variability: Available records point to strong low-frequency variability in the Arctic system, complicating both change detection and attribution. Regarding detection, computed SAT trends depend greatly on the time period and region examined. For example, SAT observations for the Arctic can be manipulated to demonstrate a strong positive trend larger than that for the Northern Hemisphere (1970 to present), essentially no trend at all (1920 to present), or a positive trend no larger than that for the Northern Hemisphere (the 20th century as a whole). SAT data for the Arctic Ocean with suitable temporal and spatial coverage exist only for the satellite era, i.e., the past 25 years. Attribution must acknowledge the important role of natural atmospheric modes, including the Northern Annular Mode (NAM) and Pacific Decadal Oscillation (PDO). From about 1970 through the mid 1990s, the NAM shifted from strongly negative to strongly positive. Attendant alterations in wind fields can account for much of the winter/spring warming over this period, especially over Eurasia (Hurrell, 1996; 
Thompson and Wallace, 1998; 2000; Thompson et al., 2000; Moritz et al., 2002). In the past decade, however, the NAM has shifted back to a more neutral state. Hartman and Wendler (2005) show that substantial warming over Alaska from 1951-2001, particularly in winter and spring, is consistent with the abrupt shift in the PDO from its negative phase from 1951 to 1976, to a primarily positive phase from 1977 to 2001. The deeper Aleutian Low during the latter period transported warm, moist air into the region. SAT trends calculated by Johannessen et al. (2004) for 1980 to 1999 (their Figure 2e,f) and those presented in the Arctic Climate Impact Assessment (ACIA) report (ACIA, 2004) for the winter seasons 1954-2003 support this view.

The NAM appears to have strong ties with sea ice. Rigor et al. (2002) show that as the NAM rose towards its positive state, changes in the regional wind field helped to break up winter ice cover along the Siberian and Alaskan coasts, resulting in thinner ice in spring that is more vulnerable to summer decay, contributing to the overall downward sea ice trend. Rigor and Wallace (2004) further argue for a multiyear lag effect. During the period 1989-1995, when the NAM was especially positive, the Arctic lost some of its store of thick, multiyear ice, due in part to a stronger flux of old ice out of the Arctic via Fram Strait. The NAM then shifted back to a more neutral state. However, the thinner ice eventually drifted back towards the Alaskan coast, helping to explain the extreme September sea ice minima of recent years. Studies also suggest that the NAM is related to the North Atlantic Thermohaline Circulation (THC), which influences (and is influenced by) Arctic warming and sea ice extent (Delworth and Knutson, 2000; Semenov and Bengtsson, 2003). This link appears to have played a role in the pronounced Arctic warming seen in the earlier part of the 20th century (Bengtsson et al., 2004).

The present paper is an attempt to shed light on the debate over the existence of Arctic amplification. We start with a review of the theoretical underpinnings (Section 2), followed by a review of model projections (Section 3) and observations (Section 4). A synthesis of these results (Section 5) leads us to conclude that there is no fundamental inconsistency between model projections and the trajectory of observed change.

\section{Theoretical Background}

Recognition of the ice-albedo feedback as an important climatic process can be traced to the early work of Croll (1875). The idea is that an initial warming leads to a reduction in areal extent of the Earth's highly reflective snow and ice cover. This results in a lower surface albedo, increased absorption of insolation, additional warming, further reduction in the areal extent of snow and ice, and so on. The icealbedo feedback is positive in that through the chain of events, the initial temperature change is amplified. It can also work in reverse, whereby an initial cooling increases 
the areal extent of snow and ice, leading to further cooling. It follows that the direct feedback on SAT should be most pronounced in the polar regions, where most of the Earth's snow and ice is found, and where strong low-level atmospheric stability will concentrate heating near the surface. The Arctic is especially sensitive to the feedback because it is much warmer than the Antarctic and closer to the melting point, thus small perturbations in the surface energy balance can substantially alter the length of the melt season.

Initiation of the feedback could result from any number of forcings, both natural (e.g., Milankovich cycles and volcanic eruptions) and anthropogenic (increased GHG concentrations and soot). While the basic feedback is typically viewed as a large-scale phenomenon involving a direct link between albedo and SAT (e.g., expressed as a change in SAT averaged for the Arctic), it is actually a much more complex amalgamation of feedbacks that vary seasonally and that have different manifestations over land and ocean, as well as locally within these regions. Many of these subtleties are still not well understood. Climate model simulations also suggest that the strength of feedbacks may change as GHG concentrations rise (Chen et al., 2003).

A host of feedbacks exist during phase change (e.g., Curry et al., 1995, 1996; Grenfell and Perovich, 2004). Because surface skin temperature is fixed during phase change, such feedbacks can be broadly viewed as precursors or attendants to the more general ice-albedo feedback involving SAT. For example, when snow melts, the grains increase in size, which reduces albedo, increases the melt rate, and further reduces the snow albedo. Over land, the melt process can be augmented by local effects, such as lateral heat transfer through the atmosphere from snowfree land to adjacent snow-covered areas. Over ocean, sea ice surface melt leads to the development of melt ponds, which reduce the albedo and accelerate melt. An increase in the fraction of leads (cracks in the ice cover) results in additional absorption of solar radiation and enhanced melt of both the edges and undersides of ice floes. Open-water fraction then increases, reducing albedo and causing further melt. Under greenhouse warming conditions, these phase-related feedbacks should start earlier in spring, leading to earlier losses of snow and sea ice.

Ice-albedo feedbacks only work in a direct sense during sunlit periods, but there can be important lagged effects that extend into autumn and winter, when solar radiation in the Arctic is small or absent (Lindsay and Zhang, 2005). From autumn through spring, sea ice is an effective insulator, limiting sensible and latent heat transfers from the relatively warm ocean (near it salinity-adjusted freezing point) to the cold overlying atmosphere (often lower than $-30^{\circ} \mathrm{C}$ ). During spring and summer an enhanced warming reduces sea ice extent and thickness, which allows the ocean to absorb additional solar radiation, increasing its sensible heat content. Come autumn, the large- scale insulating effect will be weakened owing to delayed ice formation and reduced ice extent and thickness, leading to larger heat loss from the ocean to the atmosphere. These changes will translate to higher SAT, with regional variations mainly dictated by ice thickness and concentration. In winter 
the ice will thicken, but a higher sensible heat content of the ocean results in a thinner ice cover in spring, which will be easier to melt and leads to even less ice the following autumn. Latent heat fluxes will also increase, with more efficient trapping of longwave radiation by water vapor and slower ice growth in neighboring ice-covered areas. These effects will be partially offset by the increased radiative heat loss from the warmer surface, which reduces the ocean heat reservoir, and perhaps also by increased cloud cover that blocks more incoming solar radiation. As greenhouse warming matures, these heat fluxes should be further enhanced in magnitude and will extend into winter, ultimately causing changes in SATs over the ocean that are larger than those over land.

A key determinant of the overall rate of Arctic warming will be the extent to which extra heat gained by atmospheric, ocean, and/or terrestrial reservoirs in spring/summer can be carried through winter so as to perpetuate the feedback. While the ocean has a much higher heat capacity than does the atmosphere, substantial energy can be stored within Arctic soils. This underscores the importance of realistic soil-moisture and permafrost representations in climate models, and any shortcomings may help explain differences between observed and model-projected changes in SAT over high-latitude land areas.

\section{Model Projections}

Holland and Bitz (2003) summarize annual SAT changes projected by 15 different coupled Atmosphere Ocean General Circulation Models (AOGCMs). These represent 20-year averages from transient simulations centered over the year of doubled carbon dioxide, assuming an annual increase of $1 \%$ per year. All 15 models exhibit Arctic amplification. Temperature increases in high latitudes exceed those at low latitudes by factors ranging from two to four (Figure 1). There are many reasons for the scatter, including differences in model resolution, the degree of ocean coupling, differing initial sea ice thickness and extent, as well as the varying treatments of sea ice, snow, soil moisture, sulfate aerosols and cloud cover. Another contributor is low-frequency climate variability inherent in each simulation. These mature greenhouse-world realizations also show substantial differences in the seasonality and spatial patterns of change. The strongest warming tends to be focused over the Arctic Ocean but with regional differences. The timing of maximum temperature change varies between autumn and spring, associated primarily with thinning and retreat of the sea ice cover. Not surprisingly, the models with the thinnest initial ice cover tend to exhibit the strongest Arctic amplification.

An objective of the Arctic Climate Impacts Assessment (ACIA) project (ACIA, 2004; http://www.acia.uaf.edu/) is to provide predictions of future Arctic climate to assist policy makers in planning for Arctic change. The ACIA includes simulations from five different coupled AOGCMs: (1) CGCM2 (Canadian Climate Center, Canada, or CCC); (2) CSM (National Center for Atmospheric Research, 


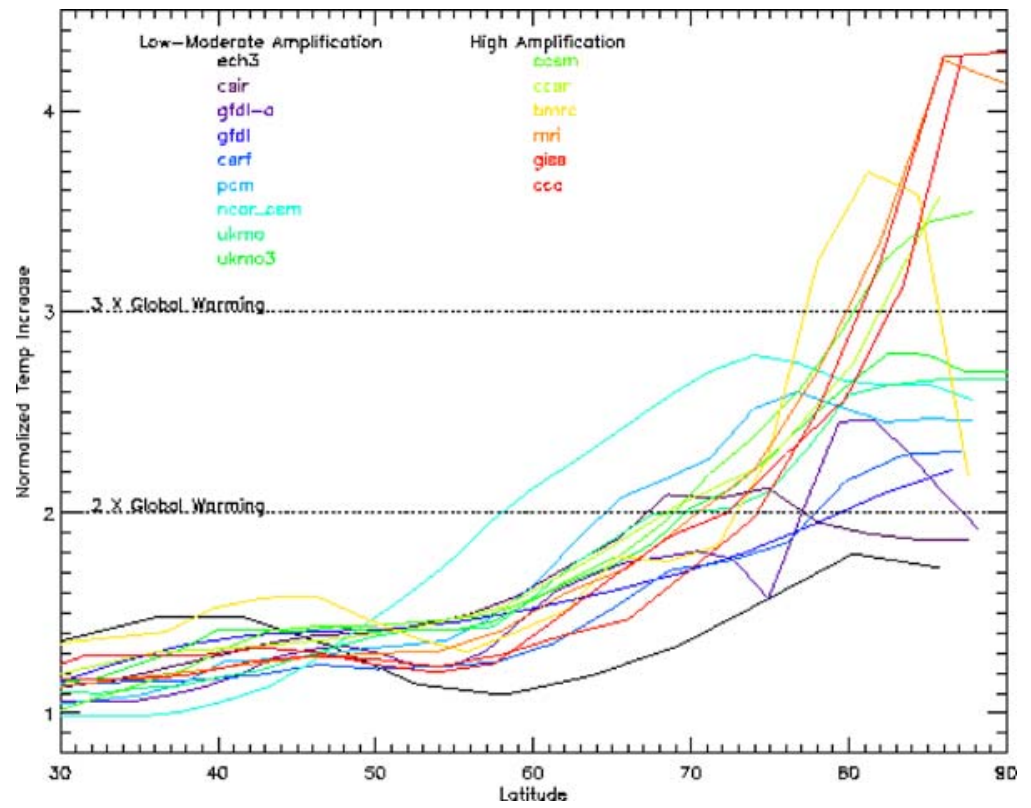

Figure 1. Comparison of model-simulated annual-average SAT change for doubled carbon dioxide concentrations. Results for each model are expressed as the normalized temperature increase by latitude compared to the global average increase for that model. (From Holland and Bitz, 2003).

USA); (3) ECHAM4/OPYC3 (Max Plank Institute, Germany); (4) GFDL (Geophysical Fluid Dynamics Laboratory, USA) and; (5) HadCM3 (United Kingdom Meteorological Office, United Kingdom). Model predictions represent the transient mean responses to the "middle of the road" expectations for future GHG concentrations, the so-called B-2 emissions scenario (Nakicenovic, 2000). Projections are created for three 20-year-average time slices: 2010-2029 (emerging greenhouse state), 2040-2059 (intermediate greenhouse state), and 2070-2079 (mature greenhouse state). Each is expressed in terms of SAT change with respect to the present day reference period, taken as the average for 1980-1999 for each model (http://zubov.atmos.uiuc.edu/ACIA/).

General features of these model projections can be assessed by evaluating output from the five- model group averages. For the mature greenhouse state (2070-2089), the annual mean temperature change $\left(4-5^{\circ} \mathrm{C}\right)$ is largest over the Arctic Ocean. The signal is dominated by changes from October through February, and especially October through December, when projected Arctic Ocean warming exceeds $9{ }^{\circ} \mathrm{C}$ in some models. The same basic pattern is evident in the 2040-to-2059 time slice, but with smaller temperature changes. The location, seasonality, and evolution of the changes indicate that feedbacks and processes related to the retreat and thinning of sea ice play a dominant role.

More appropriate for comparisons with the trajectory of observed SAT change (Section 4) are projections for the near future (2010-2029). The SAT increase in 

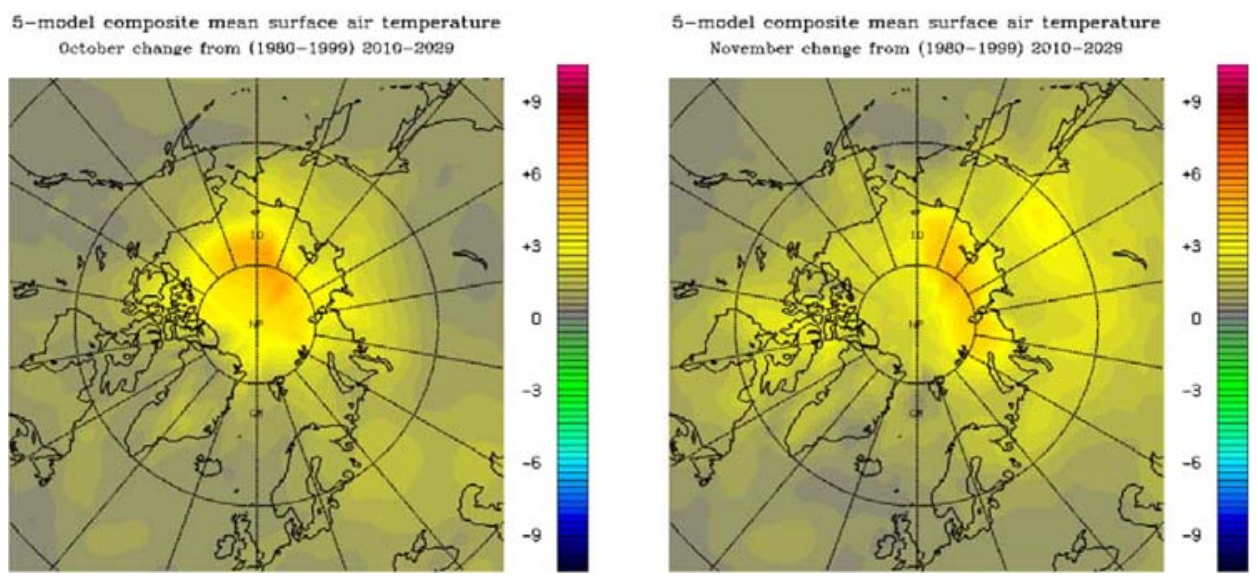

Figure 2. SAT changes for October (left) and November (right) from the ensemble of five models participating in the Arctic Climate Impact Assessment (ACIA) project. Plots display mean SAT mean (deg. C) predicted for 2010 to 2029 minus those for 1980 to 1999. Plots were obtained from the University of Illinois ACIA site at http://zubov.atmos.uiuc.edu/ACIA/.

the 5-model-ensemble, annual-mean field is widespread but much less dramatic. The warming is located primarily in the eastern Arctic Ocean and ranges from 1 to $2{ }^{\circ} \mathrm{C}$. Some areas outside of the Arctic show change of comparable magnitude. When segregated by season, however, the Arctic Ocean signal occurs primarily in October and November (Figure 2). The October pattern points to a delay in the freeze-up of the multiyear ice surface. The November pattern is indicative of less extensive and/or thinner ice in the marginal seas north of Siberia. While terrestrial changes in SAT are smaller than those for the Arctic Ocean, they also contribute to the Arctic amplification signal. Warming over northern Siberia is substantial in November and may coincide with changes in the southern extent of snow cover.

Echoing model comparisons by Holland and Bitz (2003), the projections differ widely among the five models. This is illustrated in projected changes for the nearfuture period 2010-2029 from each model for November and April (Figures 3 and 4). In November the CCC model projects the largest warming on the Siberian side of the Arctic Ocean. While ECHAM4 also shows some areas of strong ocean warming, warming of comparable magnitude is depicted over the Eurasian continent. A somewhat similar pattern appears in the GFDL field, but with more pronounced SAT increases in the Kara/Laptev/East Siberian seas as well as over north-central North America. The Arctic Ocean warming is much more dramatic in HadCM3. By comparison, the CSM simulation shows no evidence of prominent warming over the Arctic Ocean, suggesting that its sea ice cover is less sensitive to increasing GHGs. It is not until the 2070-2089 time slice that this model depicts a strong Arctic Ocean warming. It is important to note that all of the models also predict areas of cooling, albeit widely differing in location. 

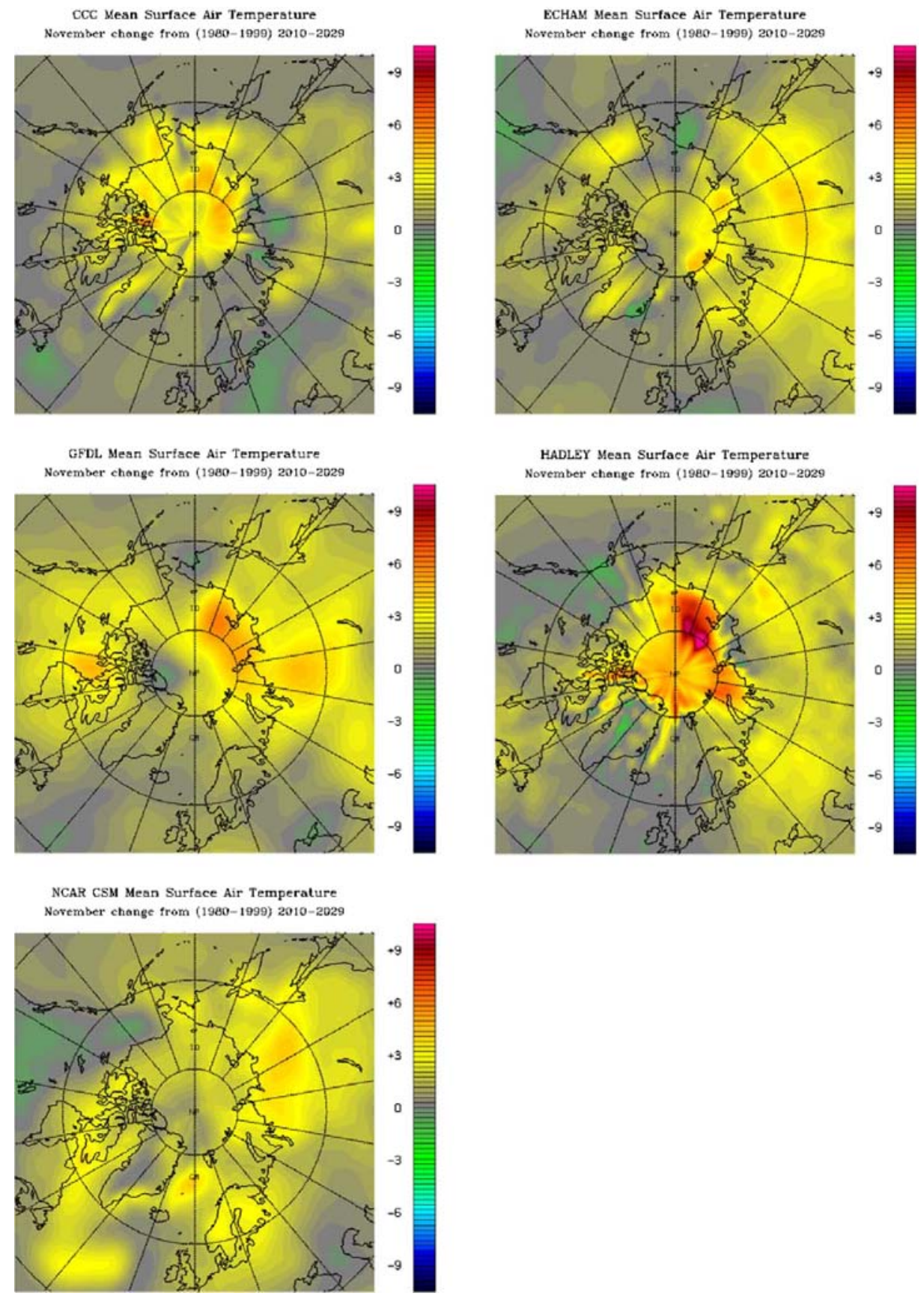

Figure 3. SAT changes (deg. C) for November expressed as averages for the period 2010 to 2029 minus those for the period from 1980 to 1999 for each of the five ACIA models. Upper left: Canadian Climate Center, upper right: European Center, Hamburg, middle left: Geophysical Fluid Dynamics Laboratory, middle right: Hadley Center, bottom left: NCAR Community System Model. Plots were obtained from the University of Illinois ACIA site at http://zubov.atmos.uiuc.edn/ACIA. 

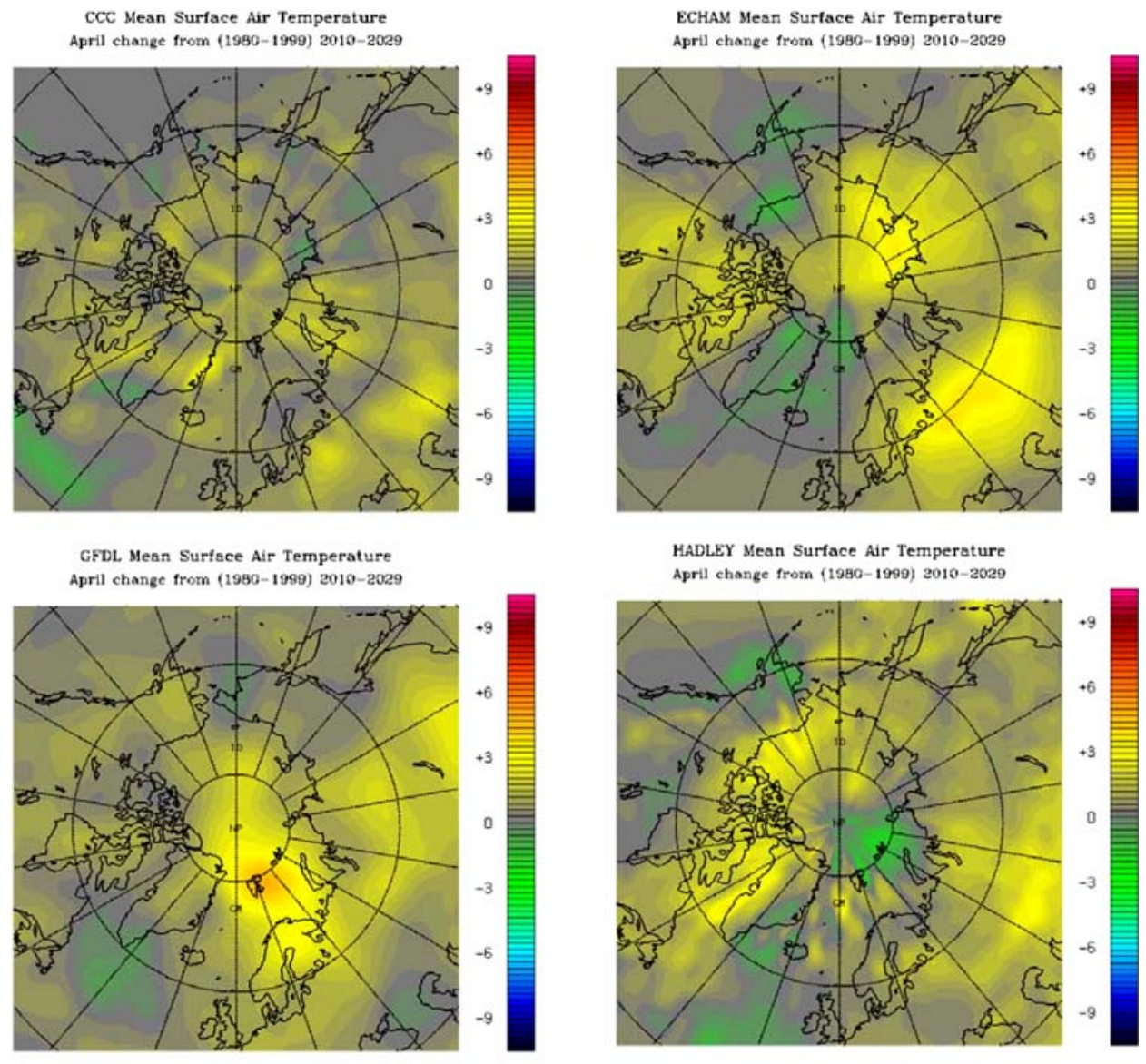

NCAR CSM Mean Surface Air Temperature

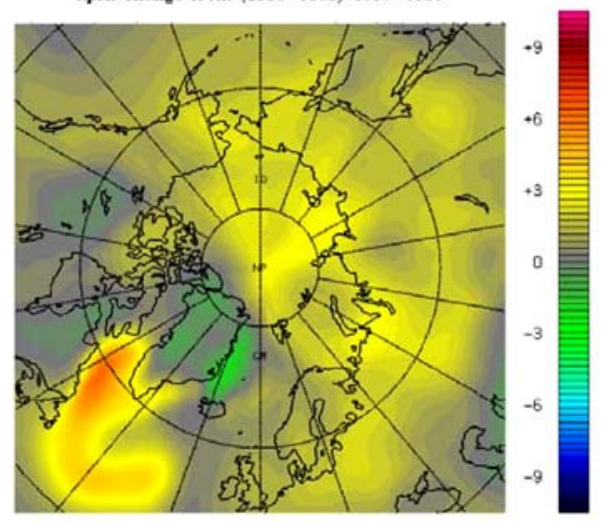

Figure 4. Same as Figure 3, but for April. 
Simulations for April display generally smaller SAT changes. With few exceptions, the Arctic Ocean does not stand out relative to land. Patterns of temperature change among models display little similarity. The Laptev and East Siberian seas in ECHAM4 are substantially warmer in the near- future period, as is the Barents Sea in the GFDL field. The CSM simulation again differs most from the other four in showing substantial warming in the North Atlantic. As in November, all models predict cooling in some areas.

Drawing from and building on Holland and Bitz (2003), we can identify a number of reasons for these differences. For example, some models predict significant reductions in the thermohaline circulation (THC). Owing to computing limitations, most AOGCMs exclude important physical and dynamical processes in their sea ice components. Snow cover simulations appear problematic in some models, particularly during transition seasons. Cloud cover is notoriously difficult to simulate realistically, yet is an important determinant of the surface radiation balance, and thus SAT.

While such shortcomings may call into question the veracity of the model projections, the scatter is also a reflection of low-frequency variability, an inherent part of both the real and modeled climate system. This may include NAM-like and PDO-like behavior. Some models exhibit large low-frequency variability, while in others it is weaker. Within the 2010-2029 time slice examined here (and for any other twenty-year period), each model will tend to be in a different phase of its lowfrequency variability. This is an important point and will be revisited later.

In summary, the ACIA models and those assessed by Holland and Bitz (2003) differ widely in temporal and spatial patterns of projected temperature change, but all depict warming in the Arctic strongest during the autumn/winter season. As the greenhouse state matures, the magnitude of the warming increases and becomes more focused over the Arctic Ocean rather than land. While increased realism of high-latitude physics is certainly needed, we interpret this signal as evidence of consistency between models and theory. In the 2010-2029 time slice, only three of the five models (CCC, HadCM3, GFDL) exhibit a pronounced Arctic Ocean signal, and some land areas warm just as much as the ocean. This indicates that models differ in their predicted arrival at the threshold where summer ice losses and consequent increases in ocean heat content affect ice formation the following autumn and winter, which establishes a positive feedback that leads to higher Arctic Ocean SATs.

\section{Observed SAT Time Series}

Time series of SAT in the Arctic are available from several sources, each with their strengths and weaknesses. Some measurements from land stations extend back into the 19th century, but spatial coverage is very sparse until about 1930 (Jones and Moberg, 2003; Overland et al., 2004). Measurements over the Arctic Ocean were 


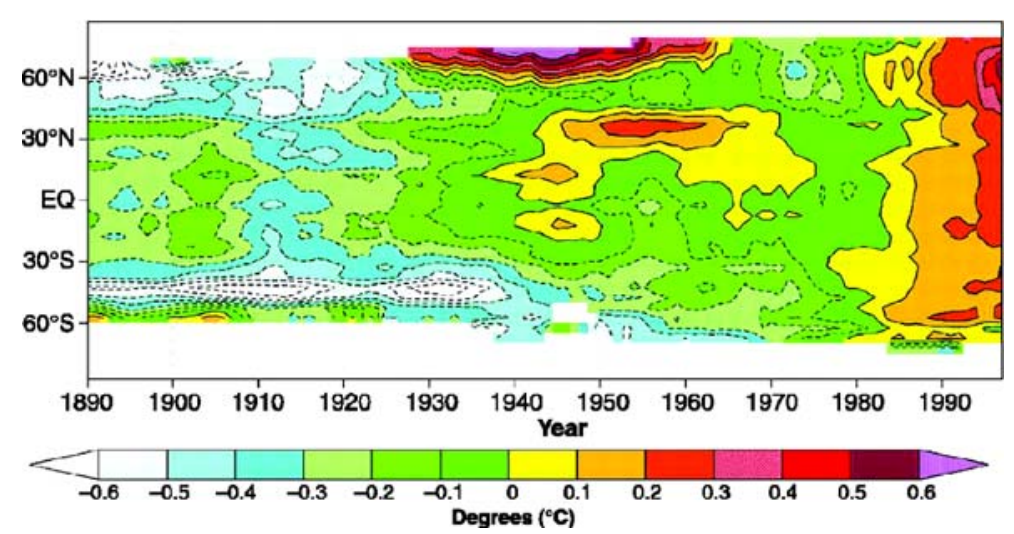

Figure 5. Observed zonally-averaged annual SAT anomalies (deg. C) as a function of latitude and time (from Alley et al., 2003, original data from Jones et al., 1999).

made at manned Russian camps drifting on thick ice floes, the so-called Russian North Pole (NP) station data set (Martin et al., 1997). These data are of high quality, but only one or two stations existed at any one time from 1950 to 1991. Autonomous buoys have been continuously deployed onto the Arctic sea ice since 1979 as a part of the International Arctic Ocean Buoy Program (IABP), but temperature measurements are of uncertain quality owing to insulating effects of snow and solar heating of the instrument housing (Rigor et al., 2000; Chen et al., 2002). Clearsky temperature retrievals from satellite sensors are available beginning in the late 1970s to early 1980s. Temporal and spatial coverage is excellent, but issues remain regarding the success of cloud masking, clear-sky biases, and sensor calibration (e.g., Chen et al., 2002; Comiso, 2003; Wang and Key, 2003). Consequently, our confidence in observed SAT changes is greater over land than over the ocean.

We begin with a review of previous studies using surface measurements of SAT. Figure 5 shows zonally-averaged, annual temperature anomalies from land stations only (data from Jones et al., 1999) as a function of latitude and time (from Alley et al., 2003; Delworth and Knutson, 2000). While this figure does not include information for the ice-covered Arctic Ocean, is clear that the high-latitude terrestrial environment has experienced significant variability - more so than have low latitudes. This is reinforced by a recent analysis of land stations including records back to the late 1800s (Overland et al., 2004). Substantial high-latitude warming from about 1920 to 1940 was followed by cooling until about 1970, then another period of marked warming that extends through the present. The earlier warming was confined largely to high latitudes. The more recent warming shown in Figure 5 is clearly very different in that it appears in essentially all latitudes examined.

Details of the earlier warming are not well known owing to the sparse data record, and conclusions drawn from different studies are not entirely consistent with each 
other. The data set originally assembled by Jones et al. (2003), and recently updated with ice-free ocean measurements (Jones and Moberg, 2003), shows significant warming between 1920 and 1944 at a few Eurasian Arctic stations in winter, in northwest Canada and the North Atlantic during spring, nowhere in summer, and at a few scattered stations in autumn. Based on these data, the 1930s warming occurred predominantly in spring and over both the North Atlantic and (more strongly) in northwestern Canada. The subsequent analysis of high-Arctic land temperature measurements by Overland et al. (2004) differs from that of Jones and Moberg (2003) in that in depicts strong positive anomalies centered on 1940 during winter over a broad area excluding the North Pacific sector. In April, the warming peaks later in the record and extends over all longitudes except the European Arctic. In summer, the anomalies are weaker but centered on the North Atlantic. In October, warming covers a broad area centered on eastern Siberia. The most conspicuous discrepancies between these analyses is for the 1930s warming event, which occurs over high-latitude Europe primarily in winter in the Overland et al. (2004) analysis. Jones and Moberg (2003) show a distinct (but not statistically significant) cooling trend during winter and spring in this area. Reasons for this disparity are unclear.

Polyakov et al. (2002) analyzed annual temperature anomalies averaged for the region north of $62^{\circ} \mathrm{N}$ over the past 125 years. Their data set yields a better description of high-latitude variability than shown in Figure 5 in that it blends measurements from land stations (primarily coastal), Russian ice camps, and buoys over the Arctic Ocean. During the most recent 17 years (1985-2001, which includes the IABP records), the computed trend for the region north of $62^{\circ} \mathrm{N}$ is about $0.6^{\circ} \mathrm{C}$ per decade, twice the corresponding Northern Hemisphere value. A trend calculated from 1920 to present, however, yields a small Arctic cooling. Over the period 1901 to 1997, the difference in the Northern Hemisphere trend and that for the Arctic is statistically insignificant. Polyakov et al. (2002) argue that the more notable feature of the Arctic is its pronounced low-frequency variability, and that this variability is probably under-sampled owing to the short data record. They further argue that the lack of enhanced high-latitude warming over the longest possible record casts doubt on the theory of Arctic amplification. From a statistical point of view, this logic is sound. Because the Arctic climate system exhibits strong variability, it follows that an analysis of SAT trends intended to assess Arctic amplification should employ the longest possible records. The assembled time series, however, is far from homogeneous, as clearly shown by Overland et al. (2004).

In an attempt to mitigate the inhomogeneity of surface observations, Johannessen et al. (2004) enhance the data set used by Polyakov et al., (2002) by including additional land stations as well as monthly averages of gridded daily SAT from the European Centre for Medium-Range Weather Forecasts (starting in 1995). These data are blended and interpolated onto a $5^{\circ}$ latitude $\times 10^{\circ}$ longitude grid. Timelatitude temperature anomalies derived from this product for latitudes north of $30^{\circ} \mathrm{N}$ (Figure 6) are consistent with those in Figure 5, with the very important distinction that the recent warming continues to increase poleward of the Arctic coast. In other 


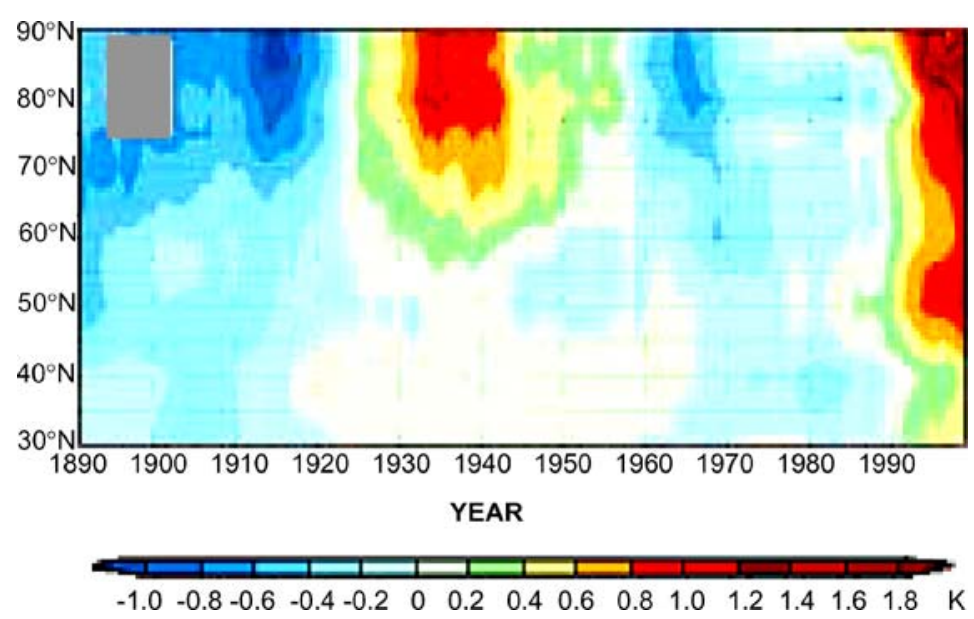

Figure 6. Zonally-averaged time series of annual SAT anomalies (deg. C) from 1891 to 1999 north of $30^{\circ} \mathrm{N}$ (from Johanessen et al., 2004).

words, this data set lends weight to Arctic amplification in recent decades. It is also more consistent with the trends identified by Overland et al. (2004).

We augment this body of evidence with further analysis of the Jones and Moberg (2003) data set of temperature anomalies, referenced to the period 1961-1990. This data set includes open-ocean temperature measurements, but none from the ice-covered Arctic Ocean. According to Johannessen et al. (2004), the lack of Arctic Ocean data does not change the basic conclusions of Polyakov et al. (2002). Figure 7 presents a time series of annual mean SAT anomalies for several different zonal bands: Arctic land $\left(65^{\circ} \mathrm{N}\right.$ to $\left.75^{\circ} \mathrm{N}\right)$, "Northern Hemisphere" $\left(0\right.$ to $\left.75^{\circ} \mathrm{N}\right)$, and "global" $\left(50^{\circ} \mathrm{S}\right.$ to $\left.75^{\circ} \mathrm{N}\right)$. Figure 8 provides a further breakdown for the higher northern latitudes. Because of sparse data coverage in early years, we limit our

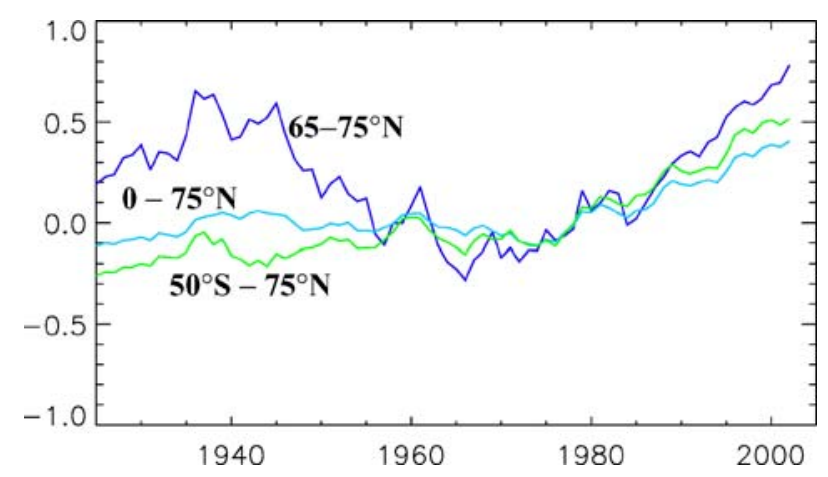

Figure 7. Anomalies in annual mean SAT (deg. C) versus time in three zonal bands (both land and ocean, but there are no data from over the Arctic Ocean) smoothed with 5-year box-car filter. Data are from Jones et al. (2003), available at http://www.cru.uea.ac.uk/cru/data/temperature/ \#datdow. 


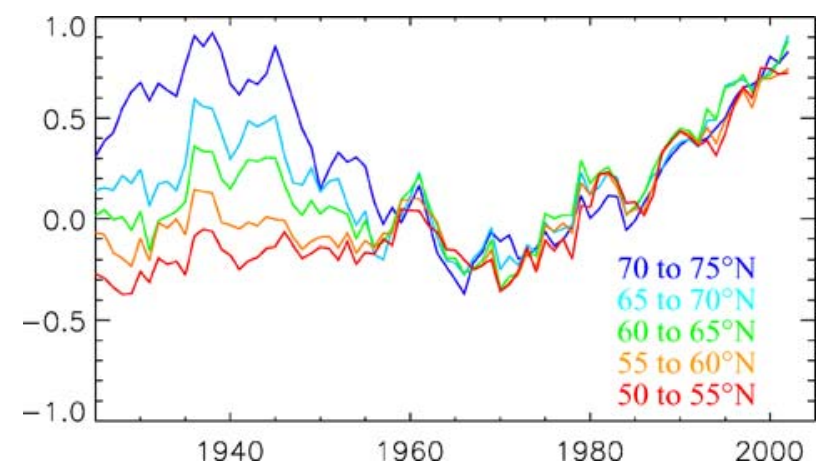

Figure 8. Same data source and processing as Figure 7, but for annual mean SAT anomalies (deg. C) in different northern high latitude zonal bands.

analysis to 1930 onwards. Anomalies for combined latitude zones are weighted by the area of each zone. At high northern latitudes $\left(65\right.$ to $\left.75^{\circ} \mathrm{N}\right)$ there was marked warming from about 1930 to 1945 , cooling to about 1970 , and warming thereafter. Consistent with Figure 6, the earlier warming period was largely confined to the Arctic. The later warming, while present for the entire Northern Hemisphere ( 0 to $75^{\circ} \mathrm{N}$ ), becomes more strongly expressed as latitude increases. The "global" anomalies show no evidence of the 1930s event owing to compensating cool anomalies in the Southern Ocean. The recent warming is clearly evident, however, albeit smaller than in the Arctic zone.

Strong seasonality is present in the anomalies (Figure 9). During the 1930s warming period, the pattern of more positive SAT anomalies in high latitudes is conspicuous during winter and autumn, weaker in spring, and nonexistent in summer. The later warming shows a different seasonal pattern. In winter there is a tendency for stronger positive SAT anomalies in high latitudes since about 1980, but not for every year. In spring and summer the warm anomaly appears later, in the mid 1980s, and in autumn it is later still, at about 1990. Between these two warm periods, primarily during winter and spring, the Arctic anomalies were generally more negative than those for the Northern Hemisphere.

We now focus on the spatial patterns of SAT changes during recent decades, recognizing that trends can depend strongly on the time interval used for the calculation (e.g., Polyokov et al., 2002). The updated Jones and Moberg (2003) data set is used to investigate the spatial variations of trends during the period after 1970 (Figure 10). This analysis does not include the Arctic Ocean. From 1970 to 2003, widespread warming is evident in all seasons. It is most pronounced during winter over the subarctic land areas of Eurasia and northwest North America, and during spring over north-central Siberia and the Bering Strait area. In autumn there are areas of cooling over western and central Eurasia and near the Bering Strait.

Clear-sky satellite retrievals of surface skin temperature help fill the gap in measurements over the Arctic Ocean. Temperature changes over the northern high 

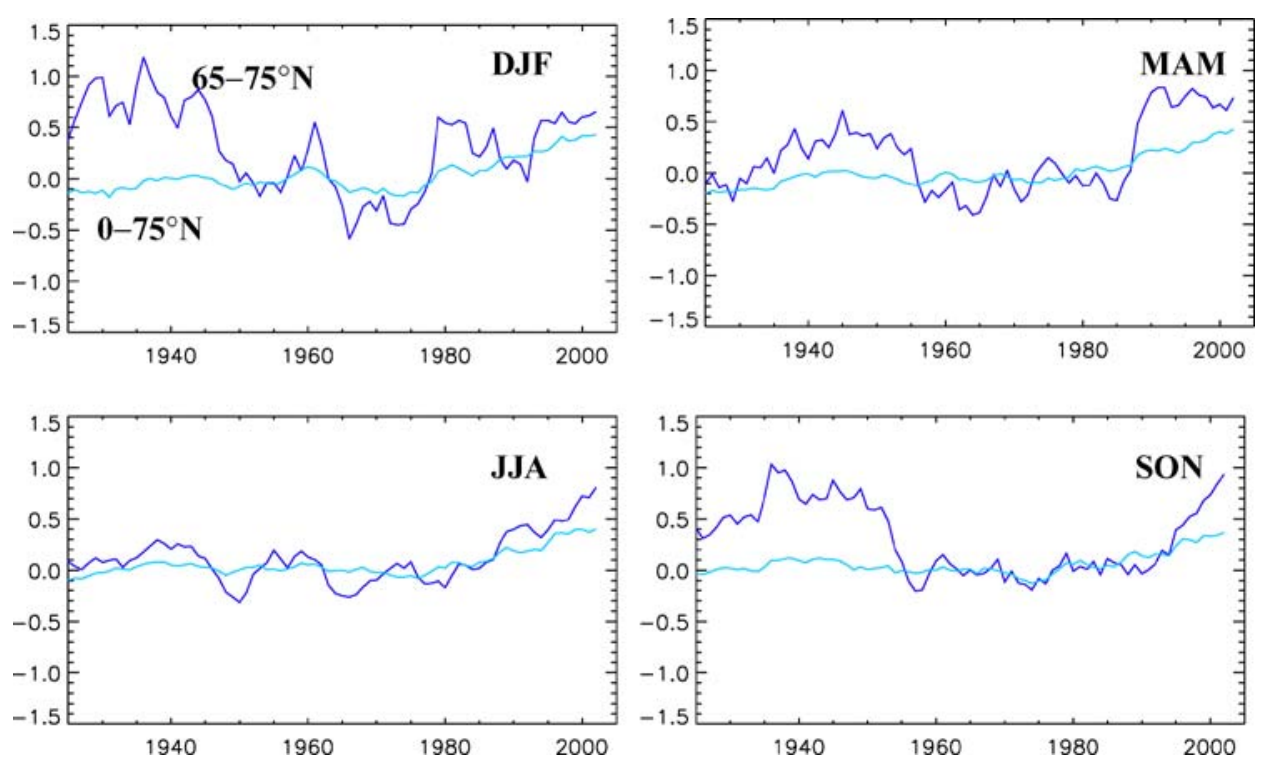

Figure 9. Same data source and processing as Figure 7, but by season (deg. C) and only for the zonal bands 65 to $75^{\circ} \mathrm{N}$ and the equator to $75^{\circ} \mathrm{N}$.

latitudes derived from Advanced Very High Resolution Radiometer (AVHRR) data appear in Figure 11 (plot updated from Comiso, 2003, which includes improvements to the original retrieval algorithms). Over the Arctic Ocean, satellite retrievals indicate general warming during the period 1981 to 2003, but with strong spatial and seasonal expressions. Arctic Ocean warming is most evident for winter, spring and autumn. There has also been some ocean warming in summer. That the ocean changes are small in summer is consistent with the large thermal inertia of the water column and the melting of sea ice. The spring and autumn warming is associated with earlier ice melt and later freeze-up. Comiso (2003) calculates that the sea ice melt season has lengthened by 10-17 days per decade. Similar changes in melt and freeze-up dates are reported by Belchansky et al. (2003), who base their independent analysis on passive microwave satellite retrievals. Note the isolated areas of pronounced ocean warming in winter (over Baffin Bay), spring (Chukchi Sea) and autumn (Beaufort Sea), which correspond to areas of known sea ice loss. Trends over land from Comiso's updated analysis differ from those in Figure 10, which are calculated for a longer period. The most conspicuous differences are in winter and summer over central Siberia, where Comiso's retrievals indicate a strong cooling while land stations show substantial warming. Trends from AVHRR also differ over northern Alaska and Scandinavia. The differing time intervals of these records contribute to these discrepancies, as may potential problems in the satellite retrievals themselves. In general, the satellite-derived trends are larger than those based on station data. 

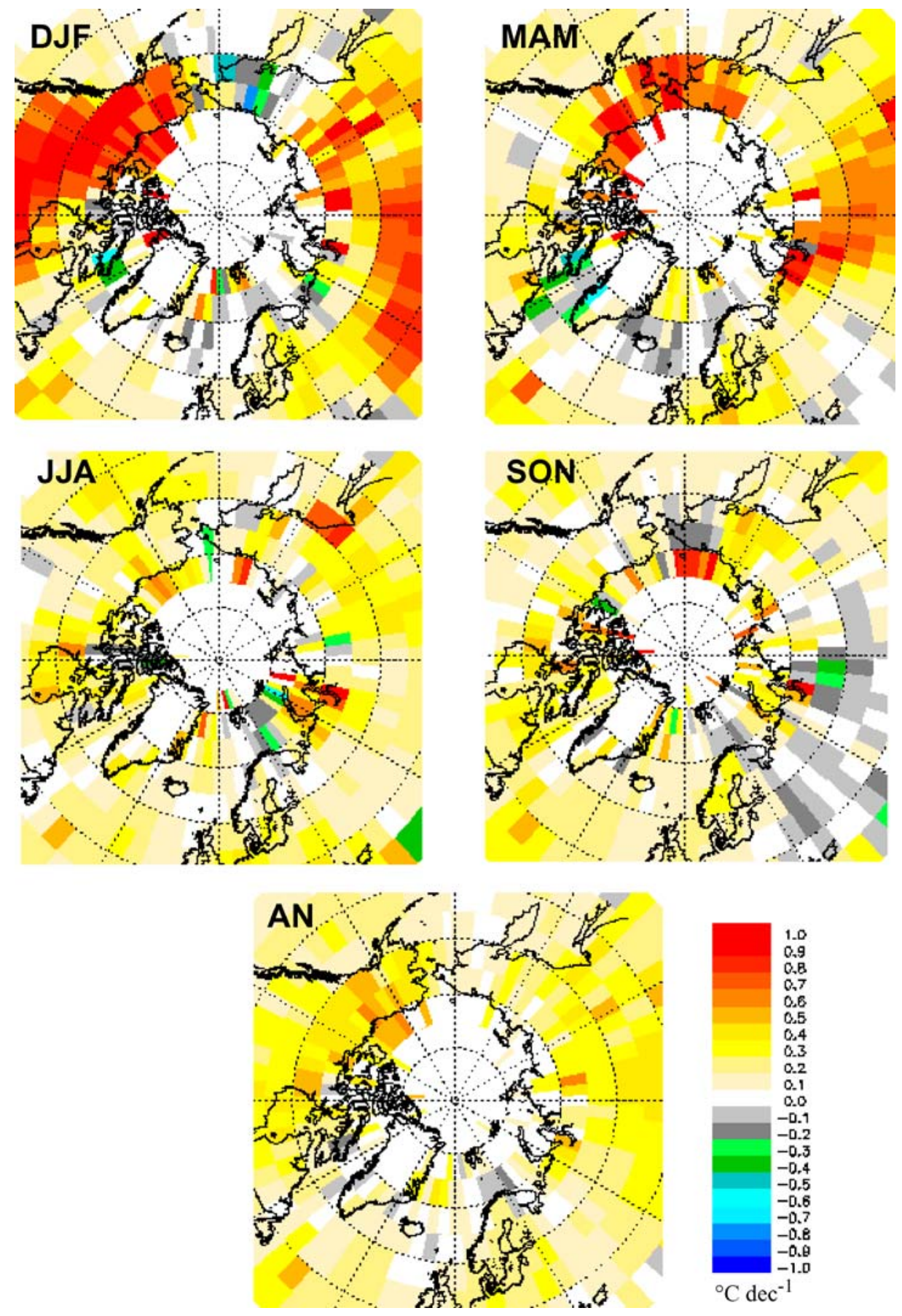

Figure 10. Decadal trends in SAT (deg. C per decade) from 1970 to 2003 calculated from the Jones and Moberg (2003) data set by season and for the annual mean (AN). Trends are only shown for grid cells with more than 17 years of data. No coverage is available for the central Arctic Ocean. 

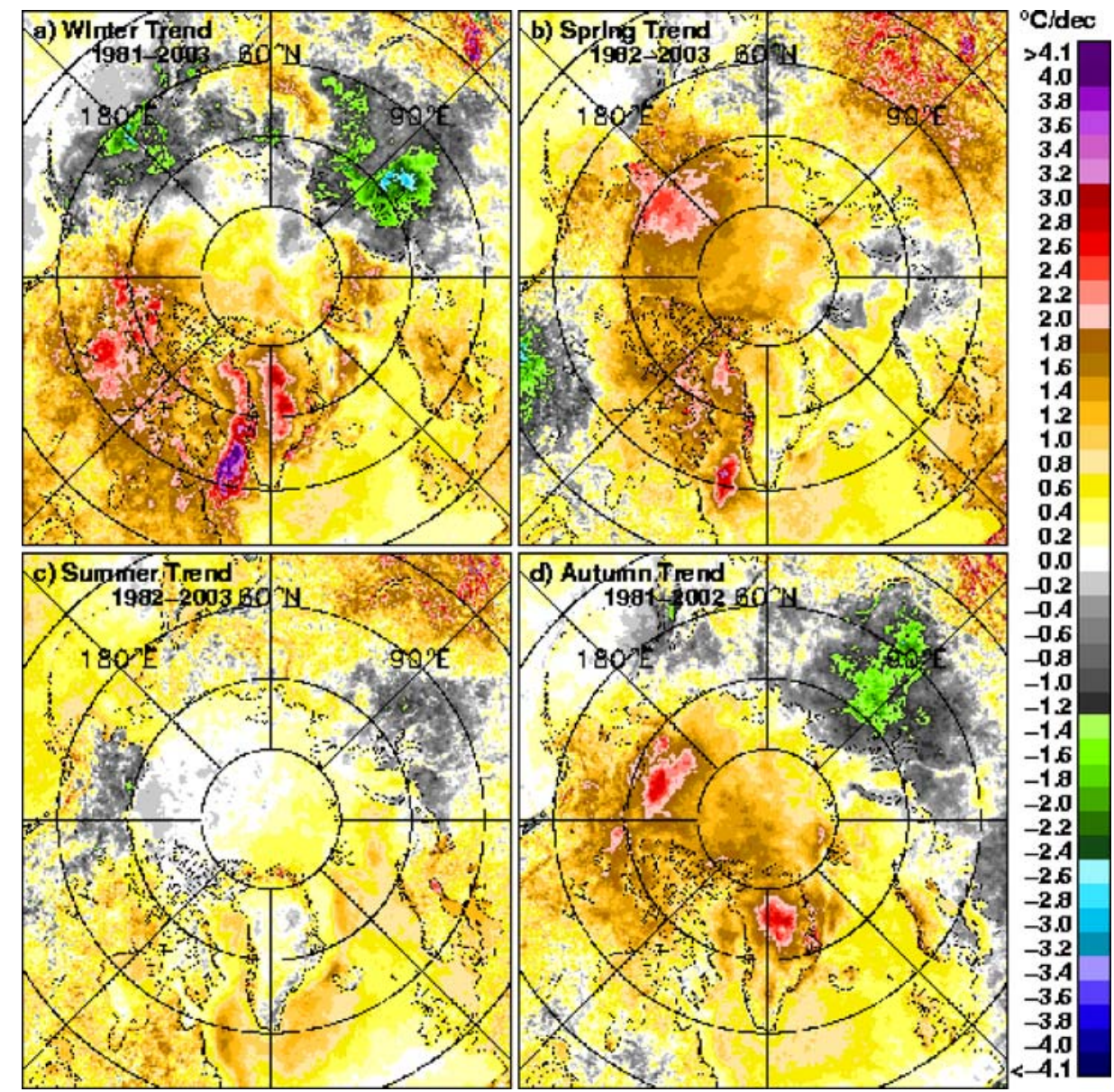

Figure 11. Trends (deg. C per decade) in Arctic surface skin temperature by season from 1981 to 2003 based on clear-sky Advanced Very High Resolution Radiometer (AVHRR) retrievals (updated from Comiso, 2003, using improved retrieval algorithms).

To summarize, all sources of SAT information reveal general warming of both ocean and land surfaces in recent decades, but with substantial seasonal and regional variability. Some areas have cooled. Discrepancies in trend calculations among the data sources relate, in part, to differences in record length and data type. It nevertheless seems clear that the warming in recent decades, the warming in the earlier part of the 20th century, as well as the cooling between them, are more pronounced in high latitudes than the Northern Hemisphere as a whole. The earlier warming has no summer signal at all, and exhibits a strong latitude dependency. The recent warming, while strongest in high latitudes, is fundamentally different in that it is part of a global phenomenon. These basic conclusions hold both with and without inclusion of SAT data from the Arctic Ocean. 


\section{Discussion}

If Arctic amplification is considered by simply asking whether SAT changes in the Arctic tend to be larger than those for the globe or Northern Hemisphere, the answer must be that it exists. Although the SAT record for high latitudes is relatively short, the coverage is far from uniform, and trends vary according to the time interval under consideration, there is little doubt that Arctic SAT changes have been especially pronounced during the last $100+$ years. The deeper question, however, is whether the recent warming in the Arctic can be viewed as an early response of the system to GHG loading.

One important piece of evidence supporting an enhanced GHG contribution is that while the earlier 20th century warming is only seen at higher latitudes, indicative of natural variability in the climate system, the recent warming is apparent in all latitude zones. Studies by Johannessen et al. (2004), based on analyses of surface data combined with simulations by two state-of-the-art global climate models, along with those by Bengtsson et al. (2004) and Delworth and Knutson (2000), support this assertion. They conclude that the earlier warming involved changes in the THC, which in turn affected sea ice extent.

Complicating the story, however, is the influence of natural atmospheric modes, such as the NAM and PDO (see Figure 6, for example). As discussed in the introduction, much of the winter/spring warming over Eurasia from the early 1970s through the mid 1990s was associated with the shift from the negative to extreme positive phase of the NAM, while warming over Alaska during the last half of the 20th century occurred as the PDO shifted from a negative to positive phase about halfway through the 50-year period.

The return of the NAM index to more neutral values in the past decade helps to explain the differing winter trend patterns in Figures 10 and 11. The results in Figure 10, based on the period 1970-2003, are strongly influenced by the change in the NAM from its negative to positive phase. By contrast, the trends in Figure 11 are based on the interval 1981-2003, which largely straddles the positive NAM period. Its influences on SAT trends are therefore smaller. The different analysis periods have conspicuous impacts on temperature changes over Eurasia. Figure 10 shows strong positive winter trends in the area, while Figure 11 shows negative trends. The more salient point, however, is that despite the differing analysis periods, warming still dominates. It also appears from Figure 9 that despite the recent retreat of the NAM, the Arctic - the land areas, at least - has continued to warm more than the Northern Hemisphere as a whole, and in all seasons.

As also discussed in the introduction, links have been demonstrated between the observed decline in sea ice extent and the NAM that involve both seasonal and multiyear lags (Rigor et al., 2002; Rigor and Wallace, 2004). These arguments focus on wind-driven changes in the ice circulation, which influence ice thickness. Rigor et al. (2002) further suggest that the thinner spring ice and increased 
open water in autumn associated with this dynamic forcing have contributed to higher SATs. Because the thinner (firstyear) ice contains more salt, it will also tend to melt at a lower temperature than older thick ice, contributing to earlier melt onset.

Subsequent work presents a different view. Using a coupled ice-ocean model driven by winds and temperatures from the NCEP reanalysis, Rothrock and Zhang (2004) simulated sea ice thickness and volume changes over the period 1948-1999. They find that although wind forcing caused much of the rapid decline in thickness from the late 1980s through the mid 1990s, the overall downward trend in thickness is better explained by a general rise in temperatures. Lindsay and Zhang (2005) arrive at a similar conclusions. While wind effects have been important., warming has reduced equilibrium ice thickness. This led to more open water in summer, thus a greater amount of solar radiation was absorbed in the upper ocean. With more heat in the upper ocean, less ice grows in autumn and winter, which then melts more easily the following summer.

In summary, we conclude that: (1) In sharp contrast to the high-latitude warming in the earlier part of the 20th century, the recent warming is part of a global signal, suggestive of external forcing; (2) Arctic amplification of this SAT signal, as well the observed decline in the sea ice cover, has been strongly influenced by lowfrequency climate variability, especially that associated with the NAM and PDO; (3) The NAM and PDO cannot neatly explain all of the changes.

How do conclusions drawn from available observations align with model predictions? For the intermediate (2040-2059) and mature (2070-2089) greenhouse states, the ensemble mean of the five models used in the ACIA shows the largest warming over the Arctic Ocean during autumn and winter. This projected change is due to the retreat and thinning of sea ice, along with increased ocean heat content, which is consistent with theory (Section 2). We submit that the projection is correct in its overall direction and location of change, a conclusion that finds further support from the simulations summarized by Holland and Bitz (2003).

The five-model-average changes for the near future (2010-2029 - the emerging greenhouse scenarios) - are of course smaller. While all of the ACIA models project a general warming during the next few decades, the spatial patterns and magnitudes of temperature change vary widely. Three of the five exhibit preferred Arctic Ocean warming during autumn, while the other two do not. Some show warming over land as large as that over the ocean. All have some areas of cooling, albeit in different locations. That the Arctic Ocean warming is more advanced in some models than others indicates that the models are in different stages of sea ice thinning and retreat. This is in part a reflection of differing treatments of processes that affect sea ice. Like the real climate system, however, these 20-year time slices are also influenced by low-frequency ( $\sim$ decadal) climate variability. This is especially evident in the highly variable time series of projected SAT from each model (not shown). Up to about 2025, time intervals can be found for which Arctic-averaged SAT from 
some models is near or even lower than present-day values. Only in more mature greenhouse conditions, when the Arctic Ocean signal emerges as a more consistent feature, do SATs consistently exceed climatological norms. Even then, the general warming trends are characterized by multi-year to decadal periods with especially strong warming, weak warming, and even cooling.

Observations show the same basic features. SAT trends are positive in most areas, but some areas show cooling. Manifesting low-frequency variability, the patterns of warming and cooling change when we alter the analysis period, but warming still dominates. Over the Arctic Ocean, AVHRR- derived SAT trends show a broad pattern of spring and autumn warming since 1981. This has resulted in lengthening of the melt season and, it seems (from ice-ocean models driven by observations), an increased sensible heat content of the upper ocean. Areas of especially strong SAT rise correspond to areas of known sea ice retreat. Although Northern Hemisphere snow cover has decreased only slightly (Armstrong and Brodzik, 2001), a positive feedback may be operating. Groisman et al. (1994) argue that the observed snow cover loss (as observed up to the time of that study) can be related to an increase in snow radiative feedback, contributing to the observed increase in spring SATs. The observed recent Arctic warming is furthermore part of a global signal.

How will the future behavior of the NAM affect Arctic amplification? Variability in the NAM from month to month and from year to year is a fundamental characteristic of internal atmospheric dynamics (e.g., Skific and Francis, 2005), while lower-frequency variability seems to involve ocean coupling. A growing weight of evidence suggests, however, that despite the return of the NAM to a more neutral state, which one might expect to retard Arctic warming, external forcing may favor an increased frequency of the warm positive phase. Many studies (e.g., Baldwin and Dunkerton, 1999; Schindell et al., 1999; Fyfe et al., 1999; Thompson et al., 2000; Gillett et al., 2003; Yumikoto and Kunihiko, 2005; Kuzmina et al., 2005) argue that cooling of the stratosphere in response to increasing carbon dioxide and methane concentrations, or even through ozone destruction by chlorofluorocarbons, may "spin up" the polar stratospheric vortex, resulting in lower Arctic surface pressures and a positive shift in the NAM. These ideas are being tested in a wide variety of models, but no consensus has yet been reached. Another idea is that the observed slow increase in sea surface temperatures (SSTs) in the tropical Indian Ocean helped to "bump" the NAM toward a preferred positive state (Hoerling et al., 2001; 2004; Hurrell et al., 2004). An intriguing aspect of this series of studies is that the SST rise may itself represent a non- linear response to GHG loading. Links with ENSO (Cassau and Terray, 2001), feedbacks on the circulation associated with factors such as sea ice loss (e.g., Semenov and Bengtsson, 2003; Delworth and Knutson, 2000), or changes from tundra to shrub vegetation (which seems to be contributing to summer Arctic warming by lowering the albedo; Wang and Overland, 2004) also require further investigation. 


\section{Conclusions}

The observed trajectory of the Arctic system over the past several decades appears to be in overall agreement with model projections. This conclusion must of course acknowledge uncertainties in model projections (in particular, model-tomodel scatter) as well as uncertainties in trend assessments of the relatively short time series of observed SAT and sea ice. Our synthesis of the available evidence points to the Arctic as in a state of preconditioning, less advanced than that shown in the ACIA simulations for 2010-2029, but setting the stage for larger changes in future decades. This preconditioning is characterized by general warming in all seasons, a lengthened melt season, and an initial retreat and thinning of sea ice, all accompanied by strong expressions of decadal-scale climate variability. The present sea ice cover is still sufficient to act as an effective insulator between the ocean and atmosphere. Before Arctic Ocean SAT changes can show the seasonality and magnitudes predicted by models for intermediate and mature greenhouse states, more ice must be removed from the system. This will allow enough additional absorption of solar radiation in summer to limit ice growth during the following autumn and winter, initiating a large-scale ice-albedo feedback. The overall consistency between observations and near-future model predictions supports the concept of Arctic amplification. We expect that the fingerprint of enhanced warming over the Arctic Ocean will soon emerge from the noise of internal low-frequency variability, at which time a new state of the Arctic will come into clearer focus.

\section{Acknowledgments}

This study was supported by NSF (J. Francis: OPP-0240791, M. Serreze: OPP0242125, OPP-0229769, OPP-0229651, ARC-0531040) and NASA. We are grateful to Drs. James Overland, Marika Holland, Cecilia Bitz, and Ron Lindsay for helpful discussions, to Elias Hunter for technical assistance, and to Dr. John Walsh for use of the ACIA simulations. We also thank the anonymous reviewers for their many helpful suggestions.

\section{References}

ACIA: 2004, 'Impacts of a Warming Arctic: Arctic Climate Impact Assessment.' Cambridge University Press.

Alley, R. B., Nordhaus, W. D., Overpeck, J. T., Peteet, D. M., Pielke Jr., R. A., PierreHumbert, R. T., Rhines, P. B., Stocker, T. F., Talley, L. D., and Wallace, J. M.: 2003, 'Abrupt climate change', Science 299, 2005-2010.

Armstrong, R. L. and Brodzik, M. J.: 2001, 'Recent Northern Hemisphere snow extent: a comparison of data derived from visible and microwave sensors', Geophys. Res. Lett. 28(19), 3673-3676.

Baldwin, M. P. and Dunkerton, T. J.: 1999, 'Propagation of the Arctic Oscillation from the stratosphere to the troposphere', J. Geophys. Res. 104, 30,937-30,946. 
Belchansky, G. I., Douglas, D. C., and Platonov, N. G.: 2003, 'Duration of the Arctic melt season: Regional and interannual variability, 1979-2001,' J. Climate 17, 67-80.

Bengtsson, L., Semenov, V. A., and Johannessen, O. M.: 2004: 'The early twentieth-century warming in the Arctic - a possible mechanism', J. Clim. 17, 4045-4057.

Cassau, C. and Terray, L.: 2001, 'Dual influence of Atlantic and Pacific SST anomalies on the North Atlantic/Europe winter climate', Geophys. Res. Lett. 30, 3195-3198.

Cavalieri, D. J., Parkinson, C. L., and Vinnikov, K. Y.: 2003, '30-year satellite record reveals contrasting Arctic and Antarctic decadal sea ice variability', Geophys. Res. Lett. 30, 1970, doi:10.1029/2003GL018031.

Chapin, F. S. III, Sturm, M., Serreze, M. C., McFadden, J. P., Key, J. R., Lloyd, A. H., McGuire, A. D., Rupp, T. S., Lynch, A. H., Schimel, J. P., Beringer, J., Chapman, W. L., Epstein, H. E., Euskirchen, E. S., Hinzman, L. D., Jia, G., Ping, C.-L., Tape, K. D., Thompson, C. D. C., Walker, D. A., and Welker, J. M.: 2005, 'Role of land-surface changes in Arctic summer warming', Science 310, 657-660.

Chen, Y., Francis, J. A., and Miller, J. R.: 2002, 'Surface temperature of the Arctic: comparison of TOVS satellite retrievals with surface observations', J. Climate 15, 3698-3708.

Chen, Y., Miller, J. R., Francis, J. A., Russell, G. L., and Aires, F.: 2003, 'Observed and modeled relationships among Arctic climate variables', J. Geophys. Res. 108(D24), 4799, doi:10.1029/ 2003JD003824.

Comiso, J.: 2003, 'Warming trends in the Arctic from clear-sky satellite observations', J. Climate 16, $3498-3510$.

Comiso, J. C.: 2001, 'Satellite observed variability and trend in sea ice extent, surface temperature, albedo, and clouds in the Arctic', Ann. Glaciol. 33, 457-473.

Comiso, J. C.: 2000, 'A rapidly declining Arctic perennial ice cover', Geophys. Res. Lett. 29, 1956, doi:10.1029/2002GL015650.

Croll. J.: 1875, Climate and Time in their Geological Relations, a Theory of Secular Change of the Earth's Climate, Daldy, Ibister \& Co., London, p. 577.

Curry, J. A., Schramm, J. E., and Ebert, E. E.: 1995, 'On the ice albedo climate feedback mechanism', J. Climate 8, 240-247.

Curry, J. A., Rossow, W. B., Randall, D., and Schramm, J. L.: 1996, 'Overview of Arctic cloud and radiation conditions', J. Climate $\mathbf{9}, 1731-1764$.

Delworth, T. L. and Knutson, T. R.: 2000, 'Simulation of early 20th century global warming', Science 287, 2246-2250.

Dickson, R. R., Osborn, T. J., Hurrell, J. W., Meincke, J., Blindheim, J., Adlandsvik, B., Vinje, T., Alekseev, G., and Maslowski, W.: 2000, 'The Arctic Ocean response to the North Atlantic Oscillation', J. Climate 13, 2671-2696.

Fyfe, J. C., Boer, G. J., and Flato, G. M.: 1999, 'The Arctic and Antarctic oscillations and their projected changes under global warming', Geophys. Res. Lett. 26, 1601-1604.

Gillett, N. P., Graf, H. F., and Osborn, T. J.: 2003, 'Climate change and the North Atlantic Oscillation', in Hurrell, J. W., Kushnir, Y., Ottersen, G., and Visbeck, M. (eds.), The North Atlantic Oscillation: Climatic Significance and Environmental Impact, Geophysical Monograph, Vol. 134, pp. 193209.

Grenfell, T. C. and Perovich, D. K.: 'Seasonal and spatial evolution of albedo in a snow-ice-landocean environment', J. Geophys. Res. 109(C01001), doi: 10.1029/2003JC001866.

Groisman, P. Y., Karl, T. R., and Knight, R. W.: 1994, 'Observed impact of snow cover on the heat balance and the rise of continental spring temperatures', Science 263, 198-200.

Groves, D. G. and Francis, J. A.: 2002, 'Variability of the Arctic atmospheric moisture budget from TOVS satellite data', J. Geophys. Res. 107(D24), 4785, doi:10.1029/2002JD002285.

Hartman, B. and Wendler, G.: 2005, 'On the significance of the 1976 Pacific climate shift in the climatology of Alaska', J. Clim. (in press). 
Hoerling, M. P., Hurrell, J. W., and Xu, T.: 2001, 'Tropical origins for recent North Atlantic climate change', Science 292, 90-92.

Hoerling, M. P., Hurrell, J. W., Xu, T, Bates, G. T., and Phillips, A.: 2004, 'Twentieth century North Atlantic climate change. Part II: Understanding the effect of Indian Ocean warming', Clim. Dyn. doi:10.1007/s00382-004-0433-x.

Holland, M. M. and Bitz, C. M.: 2003, 'Polar amplification of climate change in coupled models', Clim. Dyn. 21, 221-232.

Hurrell, J. W.: 1996, 'Decadal trends in the North Atlantic Oscillation: regional temperatures and precipitation', Geophys. Res. Lett. 23, 665-668.

Hurrell, J. W., Hoerling, M. P., Phillips, A., and Xu, T.: 2004, 'Twentieth century North Atlantic climate change. Part I: Assessing determination', Clim. Dyn. doi:10.1007/s00382-004-0432-y.

Johannessen, O. M., Bengtsson, L., Miles, M. W., Kuzmina, S. I., Semenov, V. A., Aledseev, G. V., Nagumyi, A. P., Zakharov, V. F., Bobylev, L. P., Pettersson, L. H., Hasselmann, K., and Cattle, H. P.: 2004, 'Arctic climate change: observed and modelled temperature and sea-ice variability', Tellus 56A, 328-341.

Jones, P. D. and Moberg, A.: 2003, 'Hemispheric and large scale surface air temperature variations: an extensive revision and an update to 2001', J. Climate 16, 206-223.

Jones, P. D., New, M., Parker, D. E., Martin, S., and Rigor, I. G.: 1999, 'Surface air temperature and its variations over the last 150 years', Rev. Geophys. 37, 173-199.

Karcher M., Gerdes, R., Kauker, F., and Koberle, C.: 2003, 'Arctic warming: evolution and spreading of the 1990s warm event in the Nordic seas and Arctic Ocean', J. Geophys. Res. 108(C2), 3034, doi:10.1029/2001JC001265.

Kuzmina, S., Bengtsson, L., Johannessen, O. M., Drange, H., Bobylev, L. P., and Miles M. W.: 2005, 'The North Atlantic Oscillation and greenhouse-gas forcing', Geophys. Res. Lett. 32, doi:10.1029/2004GL021064.doi:10.1029/2004GL021064, 2005.

Lindsay, R. W. and Zhang, J.: 2005: 'The thinning of arctic sea ice, 1988-2003: have we passed a tipping point?', J. Climate (in press).

Martin, S., Munoz, E. A. and Drucker, R.: 1997, 'Recent observations of a spring-summer surface warming over the Arctic Ocean', Geophys. Res. Lett. 24, 1259-1262.

Moritz, R. E., Bitz, C. M., and Steig, E. J.: 2002, 'Dynamics of recent climate change in the Arctic', Science 297, 1497-1502.

Nakicenovic, N. J. and 27 others: 2000, IPCC Special Report on Emissions Scenarios, Cambridge University Press, United Kingdom and New York, p. 599.

Osterkamp, T. E. and Romanovsky, V. E.: 1999, 'Evidence for warming and thawing of discontinuous permafrost in Alaska', Permafrost and Periglacial Processes 10, 17-37.

Overland, J. E., Spillane, M. C., and Soreide, N. N.: 2004, 'Integrated analysis of physical and biological pan-Arctic change', Climatic Change 63, 291-322.

Overland, J. E., Spillane, M. C., Percival, D. B., Wang, M., and Mofjeld, H. O.: 2004, 'Seasonal and regional variation of pan-Arctic surface air temperature over the instrumental record', J. Climate 15, 3263-3282.

Overpeck, J., Hughen, K., Hardy, D., Bradley, R., Case, R., Douglas, M., Finney, B., Gajewski, K., Jacoby, G., Jennings, A., Lamourex, S., Lasca, A., MacDonald, G., Moore, J., Retelle, M., Smith, S., Wolfe, A., and Zielinski, G.: 1997, 'Arctic environmental change of the last four centuries', Science 278, 1251-1256.

Parkinson, C. L., Cavalieri, D. J., Gloersen, P., Swally, H. J., and Comiso J. C.: 1999, 'Arctic sea ice extents, areas, and trends, 1978-1996', J. Geophys. Res. 104, 20,837-20,856.

Peterson, B. J., Holmes, R. M., McClelland, J. W., Vorosmarty, C. V., Lammers, R. B., Shiklomanov, A. I., Shiklomanov, I. A., and Rahmstorf, S.: 2002, 'Increasing river discharge to the Arctic Ocean', Science 298, 2171-2173. 
Polyakov, I. V., Alekseev, G. V., Bekryaev, R. V., Bhatt, U., Colony, R., Johnson, M. A., Karklin, V. P., Makshtas, A. P., Walsh, D., and Yulin, A. V.: 2002, 'Observationally based assessment of polar amplification of global warming', Geophys. Res. Lett. 29, 1878, doi:1029/2001GL011111.

Rigor, I. G., Colony, R. L., and Martin, S.: 2000, 'Variations in surface air observations in the Arctic, 1979-1997', J. Climate 13, 896-914.

Rigor, I. G. and Wallace, J. M.: 2004, 'Variations in the age of Arctic sea-ice and summer sea-ice extent', Geophys. Res. Lett. 31, L09401, doi:10.1029/2004GL019492.

Rigor, I. G., Wallace, J. M., and Colony, R. L.: 2002, 'Response of sea ice to the Arctic Oscillation', J. Climate 15, 2648-2663.

Robinson, D. A. and Frei, A.: 2000, 'Seasonal variability of northern hemisphere snow extent using visible satellite data', Professional Geographer 51, 307-314.

Rothrock, D. A., Zhang, J., and Yu, Y.: 2003, 'The Arctic ice thickness anomaly of the 1990s: A consistent view from observations and models', J. Geophys. Res. 108(C3), 3083, doi:10.1029/ 2001JC001208.

Rothrock, D. A. and Zhang, J.: 2004: 'Arctic Ocean sea ice volume: What explains its recent depletion?', J. Geophys. Res., 110, C01002, doi:10.1029/2004JC002282.

Schindell, D., Rind D., and Balachandran, N. et al.: 1999: 'Solar cycle, variability, ozone, and climate', Science, 284, 305-308.

Semenov, V. A. and Bengtsson, L.: 2003, 'Modes in the wintertime Arctic temperature variability', Geophys. Res. Lett. 30, 1781, doi:10.1029/2003GL017112.

Serreze, M. C., Walsh, J. E., Chapin III, F. S., Osterkamp, T., Dyurgerov, M., Romanovsky, V., Oechel, W. C., Morison, J., Zhang, T., and Barry, R. G.: 2000, 'Obsevational evidence of recent change in the northern high latitude environment', Climatic Change 46, 159-207.

Serreze, M. C., Maslanik, J. A., Scambos, T. A., Fetterer, F., Stroeve, J., Knowles, K., Fowler, C., Drobot, S., Barry, R. G., and Haran, T. M.: 2003, 'A record minimum Arctic sea ice extent an area in 2002', Geophys. Res. Lett. 30, 1110, doi:10.1029/2002GL016406.

Skific, N. and Francis, J. A.: 2005, 'Natural variability and climate change: NAO/AO signal in GISS models. Presented at the Joint Assembly of the American Geophysical Union', New Orleans, LA, 23-27 May.

Stroeve, J. C., Serreze, M. C., Fetterer, F., Arbetter, T., Meier, M., Maslanik, J., and Knowles, K.: 2005. 'Tracking the Arctic's shrinking ice cover: Another extreme September minimum in 2004', Geophys. Res. Lett. 32, doi:10.1029/2004GL021810.

Thompson, D. W. J. and Wallace, J. M.: 1998, 'The Arctic Oscillation signature in the wintertime geopotential height and temperature fields', Geophys. Res. Lett. 25, 1297-1300.

Thompson, D. W. J. and Wallace, J. M.: 2000, 'Annular modes in the extratropical circulation. Part I: Month-to-month variability', J. Climate 13, 1000-1016.

Thompson, D. W. J., Wallace, J. M., and Hegerl, G.: 2000, 'Annular modes in the extratropical circulation. Part II: Trends', J. Climate 13, 1018-1036.

Wang, X. and Key, J. R.: 2003, 'Recent trends in Arctic surface, cloud and radiation properties from space', Science 299, 1725-1728.

Wang, M. and Overland, J. E.: 2004, 'Detecting Arctic climate change using Koppen climate classification', Climatic Change 67, 43-62.

Yumikoto, S. and Kunihiko, K.: 2005. 'Interdecadal Arctic Oscillation in twentieth century climate simulations viewed as internal variability and response to external forcing', Geophys. Res. Lett. 32, L03707, doi:10.1029/2004GL021870.

(Received 4 May 2005; accepted 5 October 2005) 